\title{
Green Communication: An Effective Approach to Minimize Risk of Forgetfulness from Mobile Phone Usage
}

\author{
Aditi Mishra, Neeraj Kumar Tiwari* \\ Department of Computer Science and Engineering, Shri Ramswaroop Memorial University, Lucknow, India \\ Email: aditimishra10@gmail.com, ${ }^{*}$ neeraj.cs@srmu.ac.in
}

Received 20 February 2014; revised 10 March 2014; accepted 28 March 2014

Copyright (C) 2014 by authors and Scientific Research Publishing Inc.

This work is licensed under the Creative Commons Attribution International License (CC BY).

http://creativecommons.org/licenses/by/4.0/

(c) (i) Open Access

\begin{abstract}
The usage of mobile-phone among children increased significantly. Children are in their growing phase and cells of their body are rapidly dividing, therefore propagation of electro-magnetic (EM) radiation occurs quickly in children. The aim of the present study was to evaluate the extent of mobile-phone usage as well as its possible health effect. A total number of 455 (398 children and 57 adults, 396 urban and 59 rural) students of age group ranging from 10 - 29 years participated in this study. An "Information Gathering Chronological (IGC) model" was used for the collection and evaluation of information. The four major parameters, i.e. demographic and public uniqueness, mobile-phone consumption patterns, grievance of the "forgetfulness" symptom to the subjects and awareness about the safety measures were included to get the concise information from participants. We have observed that the prevalence of "forgetfulness" was $23.95 \%$ among mobile-phone users. The incidence of overall "forgetfulness" symptoms was $23.59 \%, 17.46 \%, 25.00 \%$ and $37.50 \%$ in low (LU), normal (NU), moderate (MU) and heavy (HU) mobile-phone users respectively. A trend for risk for "forgetfulness" was observed in HU as compared to LU in overall mobile-phone users. Three folds and nearly five folds increased risk for "forgetfulness" was found among $\mathrm{HU}$ as compared to $\mathrm{LU}$ in children $(\mathrm{p} \leq \mathbf{0 . 0 2 1 0})$ and urban area mobile-phone users respectively. No significant difference for "forgetfulness" symptoms was found in other categories (i.e. adult and rural mobile-phone users). These results suggested that the incidences of "forgetfulness" among children from urban area mobile-phone users were significantly increased.
\end{abstract}

\section{Keywords}

Cellular Phone; Electromagnetic Hypersensitivity (EHS); Self Reported Symptom; Forgetfulness

\footnotetext{
${ }^{*}$ Corresponding author.
}

How to cite this paper: Mishra, A. and Tiwari, N.K. (2014) Green Communication: An Effective Approach to Minimize Risk of Forgetfulness from Mobile Phone Usage. E-Health Telecommunication Systems and Networks, 3, 1-7. 


\section{Introduction}

Rapid advancement of technology and widespread usage of cellular phone cause detrimental effects on health. According to the Ministry of Telecommunication's current guidelines, the electromagnetic (EM) waves released from cellular phone may harm the tissues of brain among users who kept their cellular phone very closer to the ear [1]. Further, it has been suggested that the radiofrequency energy emitted by cellular phone heats up the tissues which may cause adverse effect to human health [1]. The increased usage of cellular phone among kids is skyrocketing or we can say human exposure to electromagnetic radiation is taking place in a way that, never dreamt before [2]. The cellular phones propagate a type of radiation called an electromagnetic field (EMF). Radiofrequency radiations (RFR) released by cellular phones are taken up by the skin, which will give undesirable outcome in the biological system. Children are in their growing phase and they have thinner and under-keratinized skin than adults. Therefore, they are more conducive to the absorption of electromagnetic (EM) radiation through the skin. It has been shown that the child's head absorb more EM radiation than an adult's head [3]. There are few studies, which confirm the deeper dispersion of absorbed rays in a child's head [4] [5]. It may be due to the thinness of the outer ear and head of kids [6] [7]. Huge radio frequency (RF) penetration relative to head size, and longer duration exposure were experienced among children in comparison with adults [8]. One in three youngsters sends more than 3000 texts per month. Teenagers' ages, 13 to 17 have the maximum rank of text messaging an average of 3364 mobile texts per month [9]. Radio-frequency energy emitted by mobilephone is considered as non-ionizing radiation. Non-ionizing radiation is the part of the electromagnetic spectrum which has photon energies too weak to break atomic bonds. It has a wide variety of applications in communication, industry, and medicine. Usually it causes a heating effect but extensive usage of mobile-phone may have a hazardous effect among children due to the lack of awareness. The epidemiological [10], cellular [11] and animal studies [12], have been performed for the evaluation of EM radiation and its harmful effect, but none of them have reached definite conclusions. Therefore, it is important to study possible adverse health effects among cellular phone users. In this study, we have attempted to evaluate the extent of mobile-phone usage and the potential self-reported health effects among North Indian students.

\section{Materials and Methods}

We have recruited 455 students, age group of $15.94 \pm 2.92$ (mean age \pm SD) ranging from $10-29$ years old. Most of the participants belonged from the north Indian region. A well-structured study proforma was designed to find the possible risk of Electromagnetic hypersensitivity among cellular phone users. In this study, children, and the young generation population was participated in a majority. It was observed that mostly all users of this study were from primary, secondary education or higher secondary education programs, but few participants were registered in UG or PG programs. For the collection of the information from different ethnicities, we followed the modified methodology of Kumar et al. (2012). An "Information Gathering Chronological (IGC) model” was used for collection and evaluation of the information [13].

\subsection{A Well-Structured Study Pro-Forma}

Gathering the information, including some basic facts, cellular-phone information regarding its operator services and usage and common health of users, Further, in the section of general health, self reported complaints of symptoms "forgetfulness" were also collected from cellular phone subscribers. At the end of this pro-forma, users were asked to comment on safety measures what they adopted during long and short calls. A written consent was obtained from each participant prior to inclusion in the study. To avoid the intra observer error experienced personal were involved in this survey.

\subsection{Prime Parameters}

In this study, four major parameters were included to assess the different confounding factors in order to get concise information from different sources. These parameters were (i) Demographic and public uniqueness "Table 1", (ii) Consumption patterns "Table 2", (iii) Grievance of the "forgetfulness" symptom to the subjects and (iv) Awareness about the safety measures "Table 3". 
Table 1. Demographic and social characteristics.

\begin{tabular}{|c|c|c|}
\hline S. No. & Characteristics & Classifications \\
\hline 1 & Gender & $\begin{array}{l}\text { Male } \\
\text { Female }\end{array}$ \\
\hline 2 & Educational Level & $\begin{array}{c}\text { Primary School } \\
\text { Secondary School } \\
\text { Higher Secondary School } \\
\text { UG or PG }\end{array}$ \\
\hline 3 & Family Detail & $\begin{array}{l}\text { No of Family Members } \\
\text { No of Mobile phone user } \\
\text { No of Children Below16 yr }\end{array}$ \\
\hline S. No. & Characteristics & Classifications \\
\hline 1 & Frequency of use & $\begin{array}{c}\text { Non-regular use }(<1.5 \text { years) } \\
\text { Regular use }(>1.5 \text { years })\end{array}$ \\
\hline 2 & Life-time years of use & $\begin{array}{c}\leq 1 \text { Years }-3 \text { years }> \\
\leq 3 \text { years }-5 \text { years }> \\
\geq 5 \text { years }\end{array}$ \\
\hline 3 & Number of calls per day & $\begin{array}{l}\text { Dialed calls } \\
\text { Received calls }\end{array}$ \\
\hline 4 & Hours of use per day & $\begin{array}{c}\geq 1 \text { hours } \\
<1.5 \text { hours }-3 \text { hours }> \\
\leq 3 \text { hours }-5 \text { hours }>\end{array}$ \\
\hline 5 & Mode of use & $\begin{array}{c}\text { Ringing mode } \\
\text { Vibration mode } \\
\text { Both (Ringing + Vibration) }\end{array}$ \\
\hline
\end{tabular}

Table 3. Adopted safety measures.

\begin{tabular}{|c|c|c|}
\hline S. No. & Characteristics & Classifications \\
\hline 1 & $\begin{array}{l}\text { Which ear side user holds their } \\
\text { cell phone during call? }\end{array}$ & $\begin{array}{l}\text { Left ear side } \\
\text { Right ear side }\end{array}$ \\
\hline 2 & $\begin{array}{l}\text { Do you use safety device during } \\
\text { talking on mobile phone? }\end{array}$ & $\begin{array}{l}\text { Ear phone } \\
\text { Blue tooth } \\
\text { Speaker mode } \\
\text { No device }\end{array}$ \\
\hline 3 & $\begin{array}{l}\text { Generally where you hold you're } \\
\text { mobile phone? }\end{array}$ & $\begin{array}{c}\text { Pant pocket (left or right) } \\
\text { Shirt pocket (left or right) } \\
\text { Hanging in neck } \\
\text { Mobile holder in belt } \\
\text { In bag }\end{array}$ \\
\hline 4 & $\begin{array}{l}\text { Do you switch off your mobile } \\
\text { phone in nights? }\end{array}$ & $\begin{array}{l}\text { Yes } \\
\text { No }\end{array}$ \\
\hline 5 & $\begin{array}{c}\text { Do you keep your mobile phone } \\
\text { near head during sleep? }\end{array}$ & $\begin{array}{l}\text { Yes } \\
\text { No }\end{array}$ \\
\hline
\end{tabular}

\section{Data Analysis}

The information for each subject from the questionnaire was transformed into Micro Soft Excel sheet to compute the prevalence of signs and symptoms in relation to age, sex, and duration of usage of cellular phone. Two tailed Fisher exact test was used to calculate the differences in the prevalence of "forgetfulness" symptoms among cellular phone users in four individual groups, i.e., low users (LU), normal users (NU), moderate users 
(MU) and Heavy users (HU) using Graph-pad Prism (version 3.0, Graph-pad Software, Inc., USA). The magnitude of the effect was estimated by odds ratio and its $95 \%$ confidence interval (CI). A p-value of $\leq 0.05$ was considered as statistically significant.

\section{Result}

We have randomly selected and investigated 455 cellular phone users, under student category age ranging 10 to 29 years by using predesigned study pro-forma. Prevalence of self reported symptom of "forgetfulness" symptom was analyzed among various group i.e. overall, children, adult, urban and rural mobile-phone users "Figure 1".

We have observed that the prevalence of "forgetfulness" was $23.95 \%$, respectively among cellular phone users from north Indian population. Number of cellular phone users belonging to LU, NU, MU and HU were 284 (62.41\%), 63(13.84\%), 76 (16.70\%) and 32 (7.03\%) respectively. Prevalence of "forgetfulness" symptoms was $23.59 \%$ to $\mathrm{LU}, 17.46 \%$ to $\mathrm{NU}, 25.00 \%$ to $\mathrm{MU}$ while $37.50 \%$ to $\mathrm{HU}$ among over all CP user category "Figure 2".

A trend of increased risk for the prevalence of self-reported symptoms "forgetfulness" was observed among $\mathrm{HU}$ as compared to LU. We were keen to see the incidence of "forgetfulness" symptoms among different group i.e., children, adult, urban and rural "Table 4". Three folds and nearly five folds increase risks were seen for the incidence of self reported symptom "forgetfulness" among HU in the category of children $(\mathrm{OR}=3.27, \mathrm{CI}=1.24$ 8.62, $\mathrm{p}=0.0210)$ and urban $(\mathrm{OR}=4.78, \mathrm{CI}=1.74-13.11, \mathrm{p}=0.0024)$ mobile phone users respectively. Meanwhile, no significant difference in the prevalence of "forgetfulness" symptoms was observed among HU as

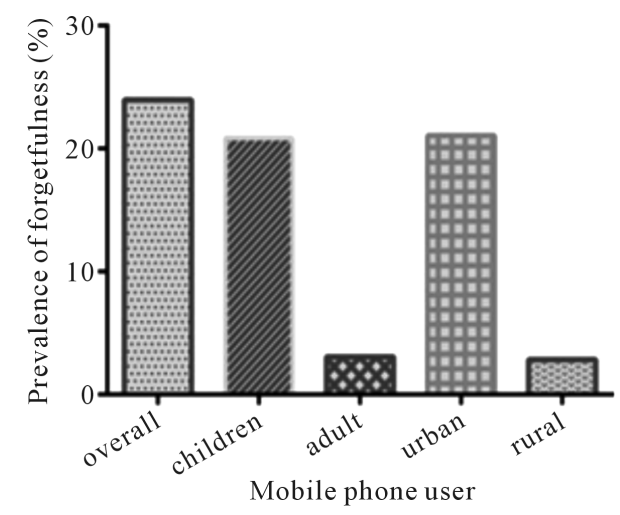

Figure 1. Prevalence of "forgetfulness" (\%) among overall, children, adult, urban and rural mobile-phone users.

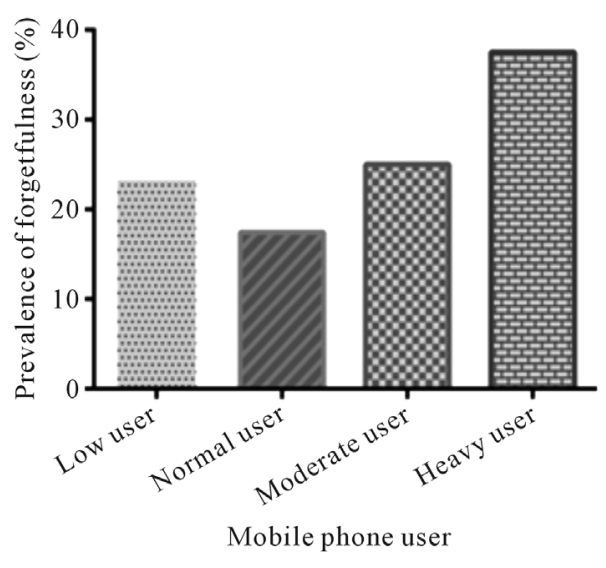

Figure 2. Prevalence of self reported symptom "forgetfulness" (\%) in LU, NU, MU and HU among over all mobile-phone users. 
Table 4. Prevalence of "forgetfulness" symptom among mobile-phone users.

\begin{tabular}{|c|c|c|c|c|c|c|}
\hline & Participants & & Low User & Normal User & Moderate User & Heavy User \\
\hline \multirow{4}{*}{ A } & \multirow{4}{*}{ Overall } & MP users (455) & $284(62.41 \%)$ & $63(13.84 \%)$ & 76 (16.70\%) & $32(7.03 \%)$ \\
\hline & & Cases of Forgetfulness (109) & 67 (23.59\%) & $11(17.46 \%)$ & $19(25.00 \%)$ & $12(37.50 \%)$ \\
\hline & & P-value & - & 0.3219 & 0.8797 & 0.0895 \\
\hline & & OR (95\%CI) & Reference & $0.68(0.33-1.38)$ & $1.08(0.60-1.94)$ & $1.94(0.90-4.18)$ \\
\hline \multirow{4}{*}{ B } & \multirow{4}{*}{ Children } & CP users (398) & $261(65.57 \%)$ & $58(14.57 \%)$ & $61(15.32 \%)$ & $18(4.52 \%)$ \\
\hline & & Cases of Forgetfulness (95) & $61(23.37 \%)$ & $9(15.51 \%)$ & $16(26.22 \%)$ & $9(50.00 \%)$ \\
\hline & & P-value & - & 0.2223 & 0.6207 & $0.0210^{*}$ \\
\hline & & OR $(95 \% \mathrm{CI})$ & Reference & $0.60(0.27-1.29)$ & $1.16(0.61-2.20)$ & $3.27(1.24-8.62)$ \\
\hline \multirow{4}{*}{$\mathrm{C}$} & \multirow{4}{*}{ Adult } & MP users (57) & 23 (40.35\%) & 5 (8.77\%) & 15 (26.31\%) & $14(24.56 \%)$ \\
\hline & & Cases of Forgetfulness (14) & $6(26.08 \%)$ & $2(40.00 \%)$ & $3(20.00 \%)$ & $3(21.42 \%)$ \\
\hline & & P-value & - & 0.6056 & 1.0000 & 1.0000 \\
\hline & & OR $(95 \% \mathrm{CI})$ & Reference & $1.88(0.25-14.20)$ & $0.70(0.14-3.40)$ & $0.77(0.15-3.75)$ \\
\hline \multirow{4}{*}{$\mathrm{D}$} & \multirow{4}{*}{ Urban } & CP users (396) & $261(65.90 \%)$ & $58(14.64 \%)$ & 60 (15.15\%) & 17 (4.29\%) \\
\hline & & Cases of Forgetfulness (96) & $60(22.98 \%)$ & $9(15.51 \%)$ & $17(28.33 \%)$ & $10(58.82 \%)$ \\
\hline & & P-value & - & 0.2895 & 0.4035 & $0.0024^{*}$ \\
\hline & & OR (95\%CI) & Reference & $0.61(0.28-1.32)$ & $1.32(0.70-2.49)$ & $4.78(1.74-13.11)$ \\
\hline \multirow{4}{*}{ E } & \multirow{4}{*}{ Rural } & MP users (59) & 23 (38.98\%) & $5(8.47 \%)$ & $16(27.11 \%)$ & $15(25.42 \%)$ \\
\hline & & Cases of Forgetfulness (13) & 7 (30.43\%) & $2(40.00 \%)$ & $2(12.50 \%)$ & $2(13.33 \%)$ \\
\hline & & P-value & - & 1.0000 & 0.2617 & 0.2733 \\
\hline & & OR $(95 \% \mathrm{CI})$ & Reference & $1.52(0.20-11.23)$ & $0.32(0.05-1.83)$ & $0.35(0.06-1.99)$ \\
\hline
\end{tabular}

N.B.-LU: Low User ( $\leq 500$ hours); NU ( $>500$ and $\leq 1000$ Hours); MU ( $>1000$ and $\leq 5000$ Hours); HU ( $>5000$ Hours); MP: Mobile phone. Fisher Exact Test was performed to obtain the p-value; OR: odds ratio; CI: confidence interval; p-value $\leq 0.05$ was considered as significant; "statistically significant increased prevalence of forgetfulness symptoms among mobile phone use.

compared to LU under both the adult and rural CP user category (Table 4).

\section{Discussion}

Cellular phones (CP) emit non-ionizing radiofrequency radiation (RFR). Children are in their growing phase and cells of their body are rapidly dividing, therefore propagation of RFR occurs quickly in the children. The increasing trend of usage of cellular phone among children was observed [14].

Children are more likely to accumulate several years of exposure to EM radiation in their life span. Children are more susceptible to EM radiation that affects rapidly growing tissue than adults. It is anticipated that the recognition of vulnerable group determined on the basis of extent of mobile-phone usage may accentuate some light on understanding of EM hypersensitivity among children mobile-phone users. Keeping these facts in the mind the present study was designed to investigate the extent of cellular phone usage as well as its potential self reported health effects among North Indian students. We have observed that the self-reported symptom "forgetfulness" was more prominent among $\mathrm{HU}$ as compared to LU in both the category male and female CP users. Nearly three to five fold increased risk was seen for the incidence of "forgetfulness" among HU while comparing to LU in the category of children and urban CP users. However, no significant difference in the prevalence of "forgetfulness" symptoms was observed among HU under both the adult and rural CP user category. Our results are in line with a recent report which suggested that the mobile-phone usage was linked with changes in cognitive function among young adolescents [15]. A recent study conducted in the medical student of Saudi Arabia 
observed that $34.27 \%$ and $40.56 \%$ of respondents have complaints of impaired concentration and memory disturbances among daily CP users. Similarly in the present study, we have also found that the prevalence of forgetfulness was $37.50 \%$ among $\mathrm{HU}$ under student category age ranging 10 to 29 years. A correlation between calling time/number of calls per day and the occurrence of self reported symptoms was observed [16], which further support our finding among self reported symptoms "forgetfulness" in North Indian students. The ear and head of children's are thinner as compared to adult [6] [7]. Therefore, children's head may absorb more EM radiation than an adults head. It has been confirmed that the deeper dispersion of absorbed radiofrequency radiation occurs in a child head [4] [5]. Further, the huge radio frequency (RF) penetration relative to head size, and longer duration exposure were experienced among children in comparison to adults [8]. The self reported symptom "forgetfulness" may be due to the extent of mobile-phone usages, which depends on the accumulation of radio frequency (RF) exposure and electric power dissipation.

Though our study has certain limitations, first the reported symptoms "forgetfulness" is the self declared ones; therefore the reported frequency may not reflect their exact incidence among North Indians. Second, since most of the students participated in this study are in the age of 12 - 18 years (65.9\%), their understandings about the exact definitions of the self reported symptoms "forgetfulness" might have affected their answers during the filling of questionnaire. Both of these limitations might have affected the outcome of this study.

\section{Conclusion}

To conclude, our results revealed that the incidence of "forgetfulness" among male children from urban mobilephone users was significantly increased. The outcome of this study should be viewed in the light of the nature of symptoms measurement (self-report) and the knowledge as well as the understandings of subjects about the symptoms. Moreover, in future, more studies in an independent cohort should be carried out to evaluate the impact of EM hypersensitivity among children mobile phone users.

\section{Acknowledgements}

We are thankful to UP Council of Science \& Technology Lucknow, India for Young Scientist Project Grant.

\section{References}

[1] News, I.C.G.S. (2008) Cell Phones Bad for Children, Pregnant Women.

[2] Kumar, N. (2012) Prevalence of Ringing Delusion among Mobile Phone Users. E-Health Telecommunication Systems and Networks, 1, 37-42. http://dx.doi.org/10.4236/etsn.2012.14006

[3] Christ, A., Gosselin, M.C., Christopoulou, M., Kuhn, S. and Kuster, N. (2010) Age-Dependent Tissue-Specific Exposure of Cell Phone Users. Physics in Medicine and Biology, 55, 1767-1783.

[4] Gandhi, O.P. and Kang, G. (2002) Some Present Problems and a Proposed Experimental Phantom for SAR Compliance Testing of Cellular Telephones at 835 and 1900 MHz. Physics in Medicine and Biology, 47, 1501-1518. http://dx.doi.org/10.1088/0031-9155/47/9/306

[5] Wiart, J., Hadjem, A., Wong, M.F. and Bloch, I. (2008) Analysis of RF Exposure in the Head Tissues of Children and Adults. Physics in Medicine and Biology, 53, 3681-3695. http://dx.doi.org/10.1088/0031-9155/53/13/019

[6] Kheifets, L., Repacholi, M., Saunders, R. and van Deventer, E. (2005) The Sensitivity of Children to Electromagnetic Fields. Pediatrics, 116, e303-e313. http://dx.doi.org/10.1542/peds.2004-2541

[7] Schuz, J. (2005) Mobile Phone Use and Exposures in Children. Bioelectromagnetics, S7, S45-S50.

[8] Hyland, G.J. (2000) Physics and Biology of Mobile Telephony. Lancet, 356, 1833-1836. http://dx.doi.org/10.1016/S0140-6736(00)03243-8

[9] Wire, N. (2011) Kids Today: How the Class of 2011 Engages with Media.

[10] Belyaev, I., Markova, E. and Malmgren, L. (2009) Microwaves from Mobile Phones Inhibit 53BP1 Focus Formation in Human Stem Cells Stronger than in Differentiated Cells: Possible Mechanistic Link to Cancer Risk. Environmental Health Perspective.

[11] Aly, A.A., Cheema, M.I., Tambawala, M., Laterza, R., Zhou, E., Rathnabharathi, K. and Barnes, F.S. (2008) Effects of 900-MHz Radio Frequencies on the Chemotaxis of Human Neutrophils in Vitro. IEEE Transactions on Biomedical Engineering, 55, 795-797. http://dx.doi.org/10.1109/TBME.2007.912636

[12] Bas, O., Odaci, E., Mollaoglu, H., Ucok, K. and Kaplan, S. (2009) Chronic Prenatal Exposure to the 900 Megahertz 
Electromagnetic Field Induces Pyramidal Cell Loss in the Hippocampus of Newborn Rats. Toxicology and Industrial Health, 25, 377-384. http://dx.doi.org/10.1177/0748233709106442

[13] Kumar, N. (2012) Assortment of Information from Mobile-phone Subscribers Using Chronological Model [IGCM]: Application and Management Perspective.

[14] Dimonte, M. and Ricchiuto, G. (2006) Mobile Phone and Young People. A Survey Pilot Study to Explore the Controversial Aspects of a New Social Phenomenon. Minerva Pediatrica, 58, 357-363.

[15] Abramson, M.J., Benke, G.P., Dimitriadis, C., Inyang, I.O., Sim, M.R., Wolfe, R.S. and Croft, R.J. (2009) Mobile Telephone Use Is Associated with Changes in Cognitive Function in Young Adolescents. Bioelectromagnetics, 30, 678686. http://dx.doi.org/10.1002/bem.20534

[16] Walsh, S.P., White, K.M. and Young, R.M. (2008) Over-Connected? A Qualitative Exploration of the Relationship between Australian Youth and Their Mobile Phones. Journal of Adolescence, 31, 77-92.

http://dx.doi.org/10.1016/j.adolescence.2007.04.004 